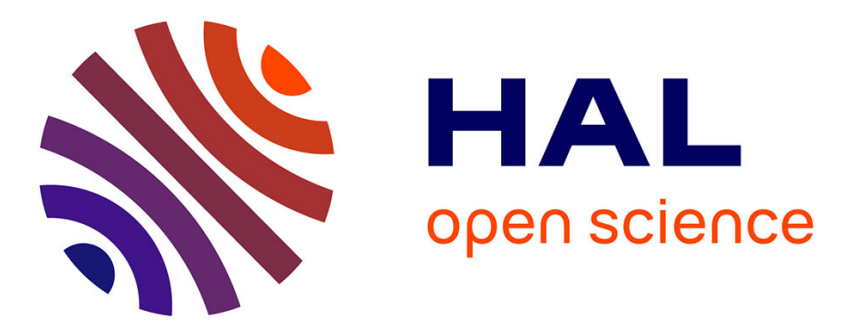

\title{
Thermal ageing induces drastic changes on mechanical and damage behavior of Sn3.0Ag0.5Cu alloy
}

\author{
Benoît Dompierre, W.C. Maia Filho, M. Brizoux, Véronique Aubin, Eric
}

Charkaluk

\section{- To cite this version:}

Benoît Dompierre, W.C. Maia Filho, M. Brizoux, Véronique Aubin, Eric Charkaluk. Thermal ageing induces drastic changes on mechanical and damage behavior of $\mathrm{Sn} 3.0 \mathrm{Ag} 0.5 \mathrm{Cu}$ alloy. Microelectronics Reliability, 2010, 50 (9-11), pp.1661-1665. 10.1016/j.microrel.2010.07.125 . hal-00517341

\section{HAL Id: hal-00517341 \\ https://hal.science/hal-00517341}

Submitted on 15 Jul 2021

HAL is a multi-disciplinary open access archive for the deposit and dissemination of scientific research documents, whether they are published or not. The documents may come from teaching and research institutions in France or abroad, or from public or private research centers.
L'archive ouverte pluridisciplinaire $\mathbf{H A L}$, est destinée au dépôt et à la diffusion de documents scientifiques de niveau recherche, publiés ou non, émanant des établissements d'enseignement et de recherche français ou étrangers, des laboratoires publics ou privés. 


\title{
Thermal ageing induces drastic changes on mechanical and damage behavior of Sn3.0Ag0.5Cu alloy
}

\author{
B. Dompierre a,b,c,d,* W.C. Maia Filho ${ }^{a}$, M. Brizoux ${ }^{\text {a }}$, V. Aubin ${ }^{\text {b,c,d }}$, E. Charkaluk ${ }^{\text {b,d }}$ \\ a Thales Corporate Services, F-92366 Meudon La Forêt, France \\ ${ }^{\mathrm{b}}$ Univ Lille Nord de France, F-59000 Lille, France \\ ${ }^{\mathrm{c}}$ ECLille, LML, F-59650 Villeneuve d'Ascq, France \\ ${ }^{\mathrm{d}}$ CNRS, UMR 8107, F-59650 Villeneuve d'Ascq, France
}

\begin{abstract}
For the $\mathrm{SnAgCu}$ alloys, previous hardness test results suggested that high temperature thermal ageing causes a quick and significant drop in the mechanical properties. However, to date, the acceleration law of thermal ageing and the relationship between thermal ageing and fatigue mechanical behavior of SnAgCu alloys are still unknown.

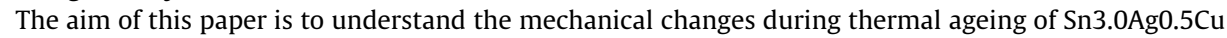
alloy and their impact on solder joint reliability under mechanical stresses. In a first part, influence of thermal ageing on mechanical behavior is analyzed by means of hardness tests, reversed tensile tests on dog-bone specimens and compression test on solder balls used for electronic components. In the second part, the impact of thermal ageing on the solder joint reliability is analyzed thanks to torsion tests on assembled boards.

The results show systematically a decrease of $20-60 \%$ of the mechanical properties or of the number of cycles to failure (in the case of torsion test). These results lead to enlarge tests conditions in order to define the fields where the influence of thermal ageing cannot be neglected.
\end{abstract}

\section{Introduction}

Since the RoHS directive implemented on July 2006, mass market leant towards lead-free solder joints for electronic assemblies and most of electronic manufacturers select SnAgCu alloys. However, the reliability of SnAgCu solder joints is still not proven in harsh environments (high temperatures and severe mechanical loadings) and long mission profile applications.

For these applications, two main subjects still need to be clarified and are linked together: reliability during mechanical (or thermomechanical) stresses and thermal ageing, which, when coupled with the precedent stresses, can significantly affect fatigue behavior for long mission profile applications. In this paper, only thermal ageing and mechanical stresses are addressed one after the other in order to clearly separate the effects of thermal ageing and of mechanical loading on the mechanical behavior and reliability.

For $\mathrm{SnPb}$ solder joint, thermal ageing is not a problem because only $250 \mathrm{~h}$ at room temperature are enough to reach the thermal aged condition [1]. In other words, during the evaluation of the reliability of leaded solder joints under mechanical loading, the alloy is in the aged condition, which is obtained after only 10 days

\footnotetext{
* Corresponding author at: Thales Corporate Services, F-92366 Meudon La Forêt, France.

E-mail address: benoit.dompierre@thalesgroup.com (B. Dompierre).
}

at room temperature. For the $\mathrm{SnAgCu}$ alloys, previous hardness test results [2] suggested that high temperature thermal ageing also causes a significant drop in mechanical properties. The principal difference with $\mathrm{SnPb}$ alloy is the needed time to reach the stabilization level. For these alloys, at least $400 \mathrm{~h}$ at $125^{\circ} \mathrm{C}$ are necessary to reach a stabilization level, which represents years of storage at room temperature. This ageing condition is often encountered in long lifetime electronic products but not taken into account during the reliability testing.

For the SnAgCu alloys, two ageing phenomena can be distinguished. First, the polycrystalline microstructure of the bulk alloy grows considerably because of thermal ageing [3,4]. Secondly, it has largely been shown that intermetallic compound (IMC) growth can be responsible for decrease in number of cycles to failure when the failure is localized in the IMC [5]. Drop in number of cycles to failure can be caused by the combination of these two mechanisms. Because the IMC matter is well known, this paper will focus on grain growth.

For $\mathrm{SnAgCu}$ alloy, previous study demonstrated the link between the grain growth and the mechanical changes [6]. After $400 \mathrm{~h}$ at $125^{\circ} \mathrm{C}$, the hardness value decreased of about $18 \%$ while the grain size increased of about $300 \%$. These previous results leaded to the analysis of the influence of thermal ageing on the mechanical and damage behavior. The damage that occurs when a material is subjected to cyclic loading is dependant on the 
mechanical behavior. In this context, the drop of mechanical properties on $\mathrm{SnAgCu}$ alloys caused by thermal ageing can induce changes in the damage behavior of this material. If a significant change in the damage behavior exists, the performance under mechanical stresses of long lifetime electronic products can be affected. The aim of this paper is to understand the mechanical changes during thermal ageing of $\mathrm{SnAgCu}$ alloys and their impact on solder joint reliability under cyclic mechanical loadings.

For electronic products, $\mathrm{Sn} 3.0 \mathrm{Ag} 0.5 \mathrm{Cu}$ is the most used composition because it presents a compromise between low melting point (near eutectic composition) and price (lower Ag rate). In this study, only Sn3.0Ag0.5Cu composition has been addressed.

This work has been divided into two steps. The first step concerns the influence of thermal ageing on mechanical behavior. Hardness tests, reversed tensile tests and compression tests were carried out. The second one is the damage analysis. Impact of thermal ageing on the solder joint reliability was analyzed thanks to torsion tests on assembled boards.

\section{Influence of thermal ageing on mechanical properties}

The aim of the first step is to improve the knowledge of the impact of thermal ageing on the mechanical behavior on the Sn3.0Ag0.5Cu alloy and to link this impact to ageing mechanisms of the microstructure of the alloy. For this purpose, three kinds of tests were carried out, in order to answer three main points.

First, hardness tests were done on bulk alloy samples for different ageing conditions (time/temperature) in order to explore the possibility of a common stabilization level for all temperatures and to define the necessary time to reach it. Then, the second point is the impact of thermal ageing on the mechanical behavior. The mechanical behavior of the alloy has been determined thanks to reversed tensile tests on dog-bone bulk samples on as-received and aged materials $\left(500 \mathrm{~h}\right.$ at $125^{\circ} \mathrm{C}$ ). Finally, the third point concerns the validation of these conclusions at the solder joint scale. Compression tests on solder balls for various diameters and ageing conditions were carried out to confirm the conclusions made on the bulk alloy.

\subsection{Hardness tests}

Hardness tests were done on bulk alloy samples after ageing at temperatures ranging from $75^{\circ} \mathrm{C}$ to $150{ }^{\circ} \mathrm{C}$ and ageing time up to $6500 \mathrm{~h}$ in order to verify if a common stabilization level for all temperatures exists and to define the necessary time to reach it.

For hardness tests, the samples were extracted from solder bars by cutting with band saw. Dimensions of the samples are $10 \mathrm{~mm} \times 10 \mathrm{~mm} \times 30 \mathrm{~mm}$ as shown in Fig. 1. All tests were realized at room temperature with a $30 \mathrm{~N}$ load applied for $10 \mathrm{~s}$. For each sample, the hardness value is obtained by averaging at least nine values to reduce uncertainty. The results presented in the following are the mean values of all measured data in each test condition.

Fig. 2 shows normalized values of the hardness for four ageing temperatures: $25^{\circ} \mathrm{C}, 75^{\circ} \mathrm{C}, 125^{\circ} \mathrm{C}$ and $150^{\circ} \mathrm{C}$. In this figure, all hardness values were divided by the hardness value at ageing time $0 \mathrm{~h}$. A value of 0.8 means that the hardness dropped of $20 \%$ from the initial value. This figure exhibits a decrease of the hardness, followed by a stabilization for $125^{\circ} \mathrm{C}$ and $150{ }^{\circ} \mathrm{C}$. The stabilization

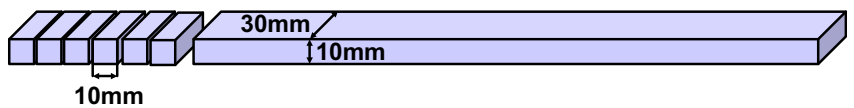

Fig. 1. Fabrication of hardness test samples.

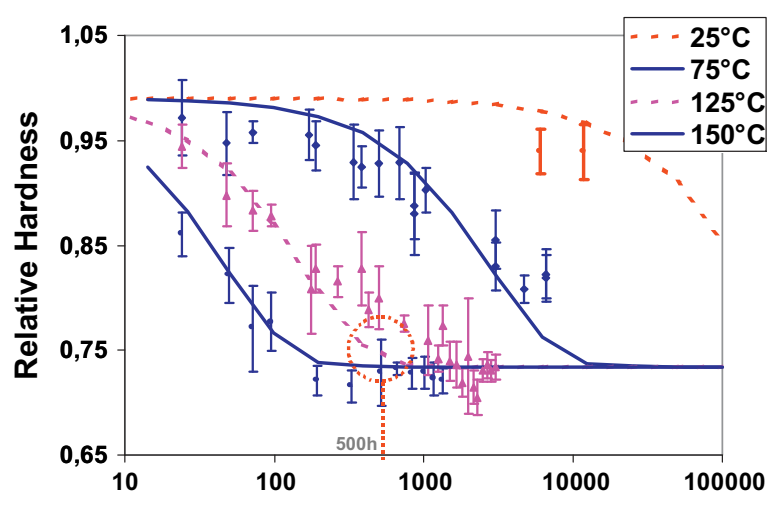

Fig. 2. Influence of ageing temperature and time on hardness.

level is the same for both temperatures, which is consistent with the hypothesis of a unique stabilization state. Following the results presented in Fig. 2, the decrease law corresponds to an exponential decay and is linked to the ageing temperature. In order to represent the observed changes, the Eq. (1) has been chosen. Parameters of this equation have been fitted with data at $75^{\circ} \mathrm{C}$ and $150{ }^{\circ} \mathrm{C}$ with a mean error of $1.9 \%$. Data at $125{ }^{\circ} \mathrm{C}$ and $25{ }^{\circ} \mathrm{C}$ are only computed; the mean error is about $2.6 \%$. The simulated curves can be seen in Fig. 2.

$H_{v}=A+B e^{-\frac{t}{\tau}}$ with $\tau=\tau_{0} \cdot e^{-\frac{E_{a}}{k T}}$

According to Fig. 2, above $125^{\circ} \mathrm{C}, 95 \%$ of stabilization is reached in about $500 \mathrm{~h}$ and this state corresponds to a drop of the initial value of about $30 \%$. The ageing time at room temperature is very inaccurate because of uncertainties, especially in the activation energy $\left(E_{a}\right)$. A variation of $10 \%$ of $E_{a}$ leads to a variation on stabilization time at room temperature by a factor 2. Considering this remark, the ageing time to stabilize at the room temperature seems to be at least 25 years.

Complementary observations have been carried out in order to explain the hardness drop during thermal ageing. Cross-polarized microscopy was used on various samples in order to determine grain sizes for each ageing condition as seen in Fig. 3. Electron backscatter diffraction method can also be used but gives similar results [7].

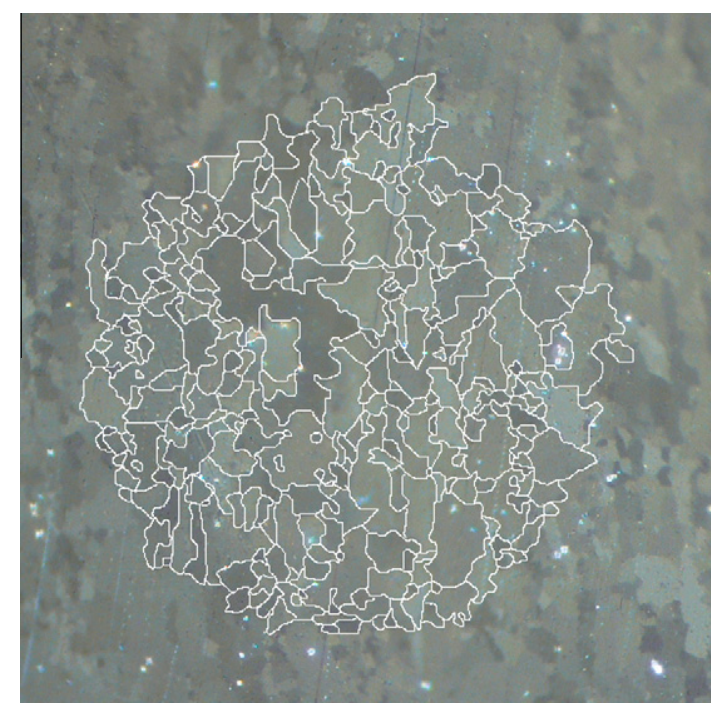

Fig. 3. Example of grain boundaries on a sample. 
For all samples, the grain size distribution was fitted with a lognormal law. Fig. 4 shows the distribution of grain sizes for Sn3.0Ag0.5Cu samples after a thermal ageing at $125^{\circ} \mathrm{C}$. It can be seen in Fig. 4 that the grain size distribution is centred around its mean value in as-received sample whereas after ageing, grains grows bigger and bigger.

An important change of the microstructure between $0 \mathrm{~h}, 72 \mathrm{~h}$ and $192 \mathrm{~h}$ of ageing can be noticed. No significant differences can be observed between the microstructure after $192 \mathrm{~h}$ and $384 \mathrm{~h}$. Differences between these two ageing conditions are probably so tiny that they are hidden by uncertainties induced by the measurement method. For these reason, no additional observation has been carried out after $400 \mathrm{~h}$ of thermal ageing at $125^{\circ} \mathrm{C}$. In Fig. 4, distributions were fitted with about 300 grains for condition "TO" and 100 grains for the others.

These complementary observations led to conclude that thermal ageing induces a grain growth linked to a decrease of the hardness, these two phenomena can be linked through the Hall-Petch law [6].

\subsection{Reversed tensile tests}

The mechanical behavior of the alloy has been determined thanks to reversed tensile tests on dog-bone bulk samples (see Fig. 5). The dimensions of the tested zone are $10 \mathrm{~mm} \times$ $10 \mathrm{~mm} \times 20 \mathrm{~mm}$. These tests were carried out on the material in two different states: on as-received material and on aged material (ageing during $500 \mathrm{~h}$ at $125^{\circ} \mathrm{C}$, until stabilization as demonstrated by hardness tests). All the tests were carried out at room temperature to analyze the changes of the mechanical behavior during the mechanical cycling for various strain amplitudes and strain rates. The strain control parameters are presented in Fig. 6. As SnAgCu alloys present a time-dependant behavior at room temperature, effects of strain rate and dwell time have to been analyzed.

Fig. 7 shows strain-stress curves for the 200th cycle for various test conditions. This cycle was chosen because the mechanical behavior is then quasi-stabilized. This figure shows that thermal ageing induces a drop of almost $30 \%$ of the stress amplitude whatever the strain amplitude tested.

The influence of strain rate on saturation stress is shown in Fig. 8. Saturation stress is the stabilized stress on hysteresis loops shown in Fig. 7. In this figure the influence of the strain rate is characterized by a decrease of $18-22 \%$ of the saturation stress for a decrease of one decade of the strain rate. This remark is valuable before and after ageing. Moreover, for each strain rate, the saturation stress is $35-40 \%$ lower for the aged condition than for T0 specimens.

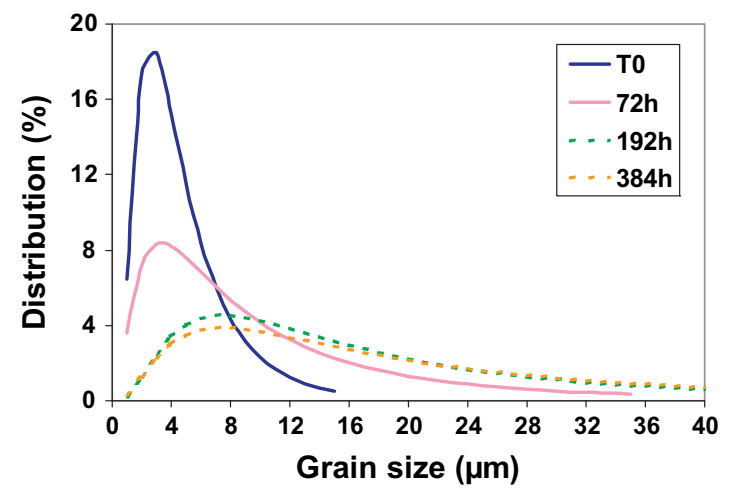

Fig. 4. Changes in grain size distribution during a thermal ageing at $125^{\circ} \mathrm{C}$.

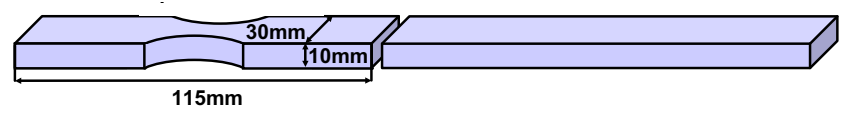

Fig. 5. Fabrication of tensile test specimens.

\begin{tabular}{|c|c|c|c|}
\hline Strain rate & $\begin{array}{c}2.10^{-3} / \\
2.10^{-4} \mathrm{~s}^{-1}\end{array}$ & \multirow{2}{*}{$\begin{array}{c}0.2 \% \\
0.6 \% ; 1 \%\end{array}$} \\
\hline Amplitude & & & \\
\hline Dwell time & $\begin{array}{c}0 \text { or } 5 \\
\text { minutes }\end{array}$ & & \\
\hline
\end{tabular}

Fig. 6. Cyclic tensile test strain control.

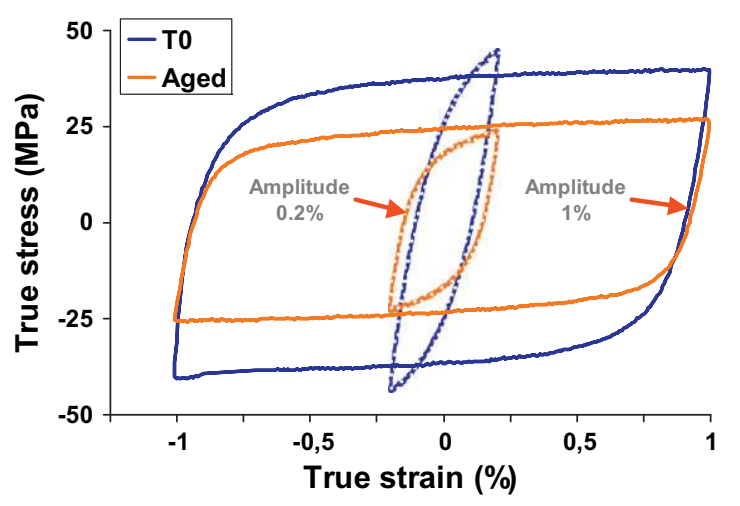

Fig. 7. Hysteresis loops at 200th cycle - strain rate: $2 \times 10^{-3} \mathrm{~s}^{-1}$.

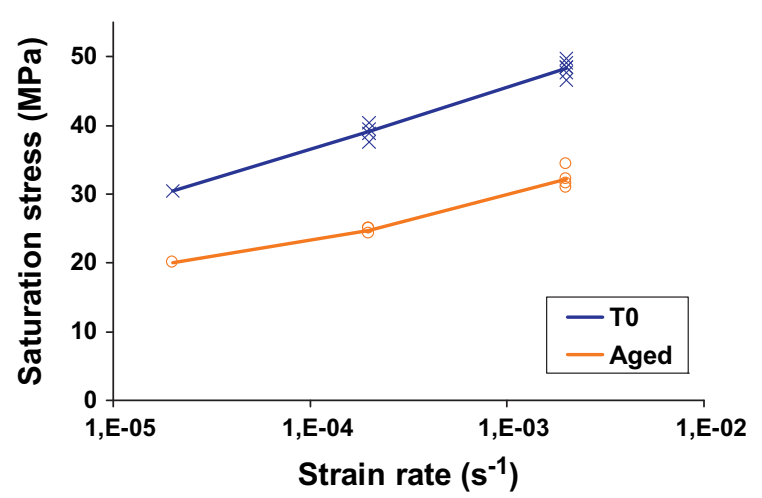

Fig. 8. Influence of strain rate on saturation stress.

\subsection{Compression tests on solder balls}

Compression tests on solder balls for various diameters and ageing conditions were carried out to confirm the conclusions made on the bulk alloy. All the tests were carried out at room temperature with a $50 \mathrm{~mm}$ diameter compression die as shown in Fig. 9. Balls are those used for real electronic components and their diameters currently measure between 250 and $760 \mu \mathrm{m}$, which is 100 times smaller than the compression die as shown in Fig. 9. Thermal ageing temperature was $125^{\circ} \mathrm{C}$ for time ranging from 0 to $2000 \mathrm{~h}$.

Because of the shape of the samples, it was impossible to realize strain rate controlled tests but only displacement controlled tests. 


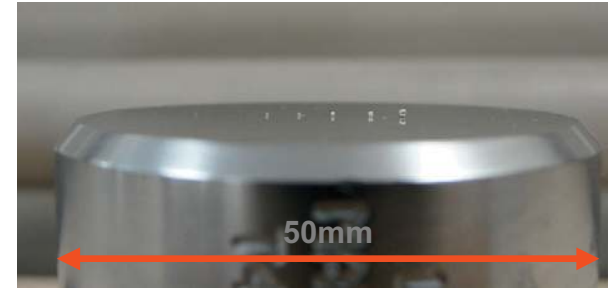

Fig. 9. Solder balls on compression die.

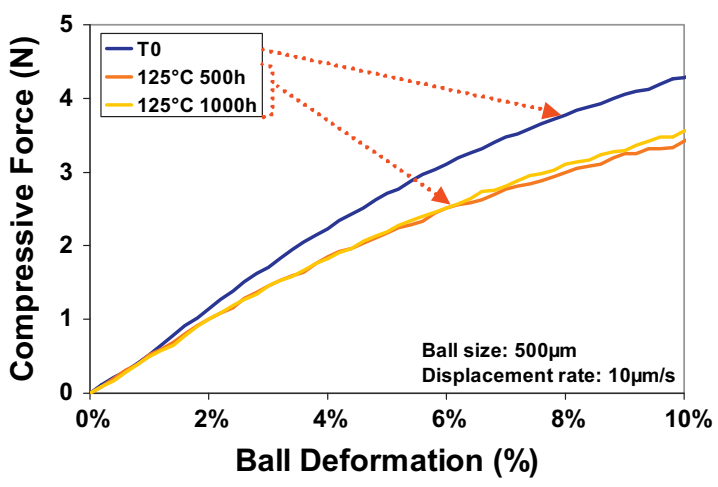

Fig. 10. Influence of thermal ageing on solder balls.

Table 1

Torsion test conditions.

\begin{tabular}{ll}
\hline Ageing conditions & $0 / 250 / 500 / 1000 \mathrm{~h}$ at $125^{\circ} \mathrm{C}$ \\
\hline Torsion conditions & Temperature: room temperature or $100{ }^{\circ} \mathrm{C}$ \\
& Maximum angle: $7{ }^{\circ}$ \\
& Angular velocity: $5 \mathrm{deg} / \mathrm{s}$ \\
& Dwell time: $1 \mathrm{~s}$ \\
\hline
\end{tabular}

For the same reason, stress curves cannot be presented. Two displacement rates were applied: $1 \mu \mathrm{m} / \mathrm{s}$ and $10 \mu \mathrm{m} / \mathrm{s}$.

Fig. 10 presents results of compression test on a $500 \mu \mathrm{m}$ diameter ball with a displacement rate of $10 \mu \mathrm{m} / \mathrm{s}$ for three conditions of thermal ageing. In Fig. 10, it can be seen that aged specimens need lower compressive force than T0 specimens for the same global ball deformation. At $10 \%$ of ball deformation (i.e. $50 \mu \mathrm{m}$ compression for a $500 \mu \mathrm{m}$ diameter ball), the difference in the compressive force between T0 and aged specimens (500 h at $125^{\circ} \mathrm{C}$ ) is about $20 \%$. Between balls aged $500 \mathrm{~h}$ and $1000 \mathrm{~h}$ at $125^{\circ} \mathrm{C}$ no difference can be found, which is consistent with results of hardness tests where stabilization is found for an ageing time of about $500 \mathrm{~h}$ at $125^{\circ} \mathrm{C}$.

\section{Torsion test}

As the impact of thermal ageing on the mechanical behavior has been demonstrated, does the drop in mechanical properties lead to a decrease in fatigue life during to cyclic mechanical stress on assembled boards?

Torsion test on assembled board is useful for fast comparative evaluation when test vehicles are using the same technological brick [8]. In the case of thermal ageing, torsion test is totally adapted because the only variable is the microstructure of the solder joint alloy. So, torsion tests were achieved for different ageing and stress conditions in order to analyze the influence of thermal ageing on the solder joint reliability.

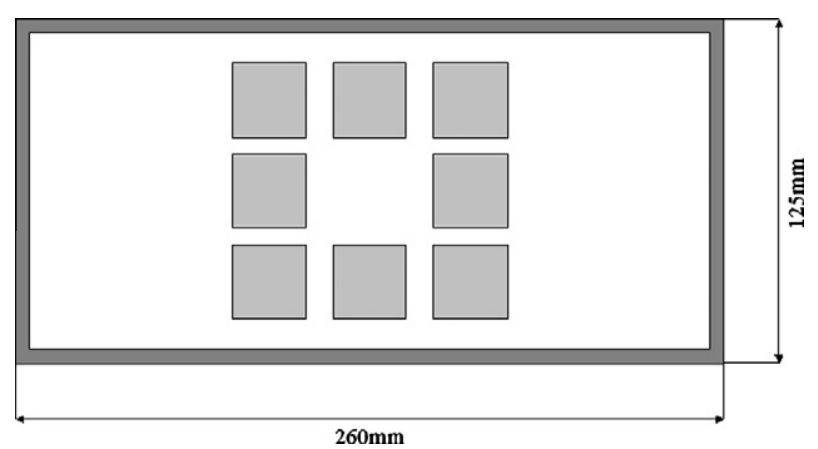

Fig. 11. Position of components on the board.

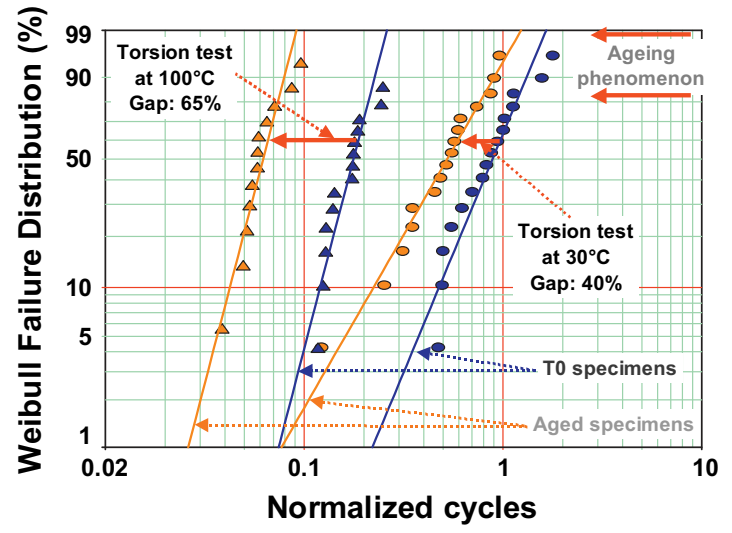

Fig. 12. Comparison of number of cycles to failure between $0 \mathrm{~h}$ and $500 \mathrm{~h}$ at $125^{\circ} \mathrm{C}$.

Eight PBGA 256 were assembled on each assembled board. Solder balls and solder paste alloy is $\mathrm{Sn} 3.0 \mathrm{Ag} 0.5 \mathrm{Cu}$ in order to be consistent with the previous results. Placement of components has been chosen in the relatively homogeneous strain area defined in a previous study [8].

Torsion tests are angle controlled. Torsion tests were carried out with the same control parameters on assembled boards in two ageing conditions: as-received and aged during various times at $125^{\circ} \mathrm{C}$. For all boards, the maximum torsion angle has been defined to $7^{\circ}$ for a total board length of $260 \mathrm{~mm}$. Conditions of torsion are summed up in Table 1 . For statistical purpose, at least 16 components have to be tested for each condition, which implies that each loading condition was realized on two different boards (see Fig. 11).

Fig. 12 shows the failure distributions for samples before ageing and after $500 \mathrm{~h}$ of thermal ageing at $125^{\circ} \mathrm{C}$ for the same conditions of torsion but for two test temperatures: room temperature and high temperature. Fig. 12 exhibits a difference in number of cycles to failure of about $40-65 \%$ between these two conditions, which is consistent with preliminary results on the alloy. Table 2 shows the decrease in number of cycles to failure after thermal ageing $500 \mathrm{~h}$ at $125^{\circ} \mathrm{C}$ for various temperatures. This number of cycles to failure is symbolized by $\eta$ which correspond to $63.2 \%$ of failure. The gap

Table 2

Influence of thermal ageing on number of cycles to failure.

\begin{tabular}{rl}
\hline Temperature of test $\left({ }^{\circ} \mathrm{C}\right)$ & Drop in $\eta$ after $500 \mathrm{~h}$ at $125{ }^{\circ} \mathrm{C}(\%)$ \\
\hline 30 & 38 \\
70 & 47 \\
100 & 65 \\
\hline
\end{tabular}


Table 3

Weibull parameters for various ageing conditions.

\begin{tabular}{cll}
\hline Ageing time $(\mathrm{h})$ & $\beta$ & Drop in $\eta$ after thermal ageing $(\%)$ \\
\hline 0 & 2.7 & 1 \\
250 & 3.1 & 33 \\
500 & 2.1 & 40 \\
1000 & 3.0 & 44 \\
\hline
\end{tabular}

Table 4

Sum up of the impact of thermal ageing under the four kind of tests presented in this paper.

\begin{tabular}{lll}
\hline Kind of test & Criterion & $\begin{array}{l}\text { Decrease after } \\
\text { thermal ageing (\%) }\end{array}$ \\
\hline Hardness & Hardness value & 30 \\
Fatigue & Stress amplitude & 30 \\
Compression & $\begin{array}{l}\text { Force at 10\% of ball } \\
\text { deformation }\end{array}$ & 20 \\
Torsion & Nf(63.2\%) & $40-65$ \\
\hline
\end{tabular}

between the two conditions increases with temperature, and is comprised between $40 \%$ and $65 \%$.

Table 3 presents the Weibull parameters ( $\beta$ and $\eta$ ) for the four ageing conditions. $\beta$ represents the slope of the curve in the Weibull failure distribution. In the four ageing conditions, $\beta$ are in the same range and is consistent with previous results on assembled board under torsion tests. This allows comparing the characteristic life by using $\eta$ (Nf 63.2\%). In these conditions of torsion, thermal ageing induces a drop in number of cycles to failure of about $40 \%$, which is significant.

Different ageing conditions have led to the same observation: thermal ageing has a negative impact on the solder joint reliability. Drop in number of cycles to failure is about $40-65 \%$. Physical failure analyses by cross-section are under progress in failed solder joints for various ageing conditions in order to understand failure mechanism. These analyses would help to understand the reduced durability.

\section{Conclusions}

The aim of this paper was to understand the mechanical changes during thermal ageing of $\mathrm{SnAgCu}$ alloys and their impact on the solder joint damage behavior under mechanical stresses.

Hardness tests were carried out on SAC305 alloy after ageing at temperature ranging between $25^{\circ} \mathrm{C}$ and $150{ }^{\circ} \mathrm{C}$. These tests led to the determination of an ageing law. For all temperatures, the stabilization level is the same and can be reached after $500 \mathrm{~h}$ at $125^{\circ} \mathrm{C}$. This stabilization level represents a decrease of $30 \%$ of the initial value.

The mechanical behavior of the alloy has been determined on dog-bone bulk samples before and after ageing $\left(500 \mathrm{~h}\right.$ at $\left.125^{\circ} \mathrm{C}\right)$.
Reversed tensile tests demonstrated that thermal ageing leads to a decrease of about $40 \%$ in the stress amplitude and about $50 \%$ is the residual stress after the stress relaxation.

Compression tests on solder balls confirmed that the impact is the same at the solder joint scale. The stabilization level is reached within the same time and the drop in the compressive force is more than $20 \%$.

As the impact of thermal ageing on the mechanical behavior was demonstrated, the aim was to confirm that the drop in mechanical properties leads to a decrease in cyclic fatigue behavior thanks to comparative torsion tests on assembled board. During torsion tests, different ageing conditions have led to the same observation: thermal ageing has a negative impact on the solder joint reliability. Drop in number of cycles to the failure is about 40-65\%.

Table 4 sums up results for all tests presented in this paper. The results show systematically a decrease of $20-60 \%$ of the mechanical properties or of the number of cycles to failure (in the case of torsion test). These results lead to enlarge tests conditions in order to define the fields where the influence of thermal ageing cannot be neglected.

Vibration and shocks must be now evaluated as two other ways reflecting operational conditions in order to analyze the impact of thermal ageing on the damage behavior of $\mathrm{SnAgCu}$ alloys and have to be explored. If these tests confirm the results of torsion tests, it would be fully demonstrated that thermal ageing is a key factor in solder joint damage behavior for products using $\mathrm{SnAgCu}$ alloy and that lifetime of long mission profile electronic products could be affected by this storage times and temperatures.

\section{References}

[1] Miyazawa Y, Ariga T. Microstructural change and hardness of lead free solder alloys. In: Proceedings of the first international symposium on environmentally conscious design and inverse manufacturing (EcoDesign '99). Tokyo, Japan; 1999. p. 616-9.

[2] Ma H, Zhang Y, Cai Z, Suhling JC, Lall P, Bozack MJ. Aging induced evolution of free solder material behavior. In: Proceedings of the 9th international conference on thermal, mechanical and multi-physics simulation and experiments in microelectronics and micro-systems (EuroSimE). Freiburg, Germany; 2008. pp. 335-46.

[3] Telang A, Bieler T, Lucas J, Subramanian K, Lehman L, Xing Y, et al. J Electron Mater 2004;33:1412-23.

[4] Xu L, Pang J. Effect of intermetallic and Kirkendall voids growth on board level drop reliability for SnAgCu lead-free BGA solder joint. In: ECTC 2006; 2006. p. 275-82.

[5] Chiu T, Zeng K, Stierman R, Edwards D, Ano K. In: Proceedings of 54th electronic components and technology conference, 2004, vol. 2; 2004. p. 1256-62.

[6] Dompierre B, Aubin V, Charkaluk E, Maia Filho W, Brizoux M. Influence of thermal ageing on long term reliability of $\mathrm{SnAgCu}$ solder joints. In: Proceedings of the 10th international conference on thermal, mechanical and multi-physics simulation and experiments in microelectronics and micro-systems (EuroSimE). Delft, Nederland; 2009. p. 342-7.

[7] LaLonde A, Emelander D, Jeannette J, Larson C, Rietz W, Swenson D, et al. J Electron Mater 2004;33:1545-9.

[8] Maia Filho W, Brizoux M, Frémont H, Danto Y. Microelectron Reliab 2007;47:1663-7. 